\author{
Barbara Pregelj \\ Universidad de Nova Gorica \\ Universidad del Litoral, Koper
}

\title{
Categoría del tiempo en la historia literaria: el caso del barroco esloveno
}

Palabras clave: historia literaria eslovena, el Barroco, la periodización, literatura eslovena

El tiempo es, sin duda, la categoría esencial de nuestra existencia y uno de los principales objetos de estudio tanto de ciencias como de humanidades. Mientras que la física, por ejemplo, relativiza el tiempo, sus tres aspectos, su flecha y hasta el tiempo mismo, la filosofía (en Heidegger, Derrida, Lacan, Deleuze) lo define precisamente mediante la aporía entre el tiempo objetivo y el subjetivo (Bilban, 2010: 24). Una dicotomía parecida entre lo particular y lo universal parecen expresar tanto la literatura, vista como un reflejo de las inquietudes concretas de la existencia humana, como también la historia y la teoría literarias como acumulaciones cualitativas de estas expresiones concretas, entre las cuales ante todo la primera opera sobre el tiempo. Por lo tanto hablar del tiempo en la historia literaria también resulta tautológico, ya que se sabe que la historia literaria es la investigación y la descripción de la literatura como una sucesión temporal (Dolinar, 2007: 23). Han sido varios -y muchos- los investigadores (Jauss, 1995; Godzich, 1998; Hutcheon, 2006) que han llamado la atención sobre distintos aspectos más o menos problemáticos referentes a lo que tradicionalmente ha sido «el campo principal de la investigación literaria» (Dolinar, 2007: 23), de manera que hoy en día es casi imposible hablar de un tema relacionado con la historia literaria sin percibir «la presencia [subjetiva, personal] del historiador literario» (Dolinar, 2007: 25).

Gracias a distintos investigadores hoy en día somos muy conscientes de que las historias literarias no son meras listas de los autores más destacados, 
sino también «unos monumentos funerarios», como sostiene Wander Melo Miranda, «erigidos para retratar la fase canónica de una nación, ofreciendo un espejo en el que se miran [...] orgullosos de su patria» (Melo Miranda, 1994: 31), lo que cabe tener presente también al hablar de la historia de la literatura eslovena, dado que, como sostiene el académico Matjaž Kmecl,

podemos afirmar que la literatura eslovena moderna nació y hasta 'ayer' se desarrolló bajo una fuerte presión de la autodemostración nacional. El concepto de la nación en el siglo XVIII estaba fuertemente ligado a la lengua y puesto que la literatura ha sido considerada 'el arte de la palabra', fue a la vez tenida por una muestra principal de la originalidad, y con ello, del derecho 'natural' a la autogobernación política y al propio estado nacional ${ }^{1}$. (Kmecl, 2004: 7)

Y sigue:

Solemos afirmar que la literatura desempeñaba un papel constitutivo-nacionalista y que el papel que correspondía a los poetas y a los escritores era parecido al de los líderes políticos. Pero aquí estoy utilizando esta constatación archiconocida porque me parece útil en su posible continuación: como los eslovenos a finales del siglo XX por fin alcanzamos nuestra independencia y logramos formar nuestro propio estado, ya no es necesario ver en la literatura eslovena el principal promotor de la nación. (Kmecl, 2004: 11)

A pesar de tratarse de un proceso centralizador apreciable en la formación de todas las literaturas nacionales (Mainer, 2006: 209-230) y por lo tanto históricamente fundado e imprescindible para la formación de la literatura eslovena, afortunadamente también entre los historiadores literarios eslovenos ha habido quienes respondieron a la llamada a la «revisión de la historia literaria eslovena» (Kmecl, 2004: 11), poniendo énfasis en algunas de las razones mnemotécnicas que solía emplear la historia literaria eslovena para destacar la literatura como una muestra de la importancia que tienen los autores canonizados para el pueblo (Hladnik, 2001: 115-118). Puesto que ya en otras ocasiones -más o menos con los mismos fines- he investigado la nación como una narración, sirviéndome del cronotopo de Mihail Bahtín, es decir, de la relación entre el tiempo y el espacio (Pregelj, 2010a), aquí no voy seguir en la misma línea -aunque sí, con el mismo concepto- sino que más bien

1 Trad. B. P. 
procuraré reflexionar «sobre la disposición de espacio y de tiempo a partir de los cuales debe empezar el relato de la nación» (Bhabha, 2006: 92), esto es, analizaré algunos aspectos del discurso de la historia literaria -centrándome en la categoría del tiempo- como si fuera una narración cualquiera.

A la luz de las teorías de los polisistemas, la literatura eslovena suele considerarse una literatura periférica y pequeña (Ožbot, 2006; Ožbot, 2011), de ahí que en ella hasta el siglo XIX pueda percibirse un fuerte policentrismo que causa un desarrollo desigual en varios centros distintos (Trieste, Klagenfurt, Viena, Graz, Liubliana). Es en el siglo XIX cuando a causa del interés por las cuestiones nacionales los acontecimientos culturales principales se centralizan ${ }^{2}$. Y es el tándem creativo de France Prešeren (1800-1848) y Matija Čop (1797-1935) el que trae a la literatura eslovena nuevos enfoques, relacionados con el coetáneo movimiento romántico europeo (Pregelj, 2010b: 284-290).

Las rupturas del Romanticismo esloveno para la literatura son decisivas: en primer lugar, se establece la distinción entre la literatura canonizada y la literatura popular ${ }^{3}$, y también entre la literatura culta y la tradicional ${ }^{4}$. En segundo lugar se establece la norma de la lengua eslovena (Jesenšek, 2010: 14-18), lo que influye mucho en la creación literaria, sobre todo en autores de Eslovenia oriental (Pretnar, 1997: 75), como lo pudo experimentar Stanko Vraz (1810-1851), el primer traductor de los romances españoles al esloveno (Pregelj, 2006: 330). Y en tercer lugar, la traducción -acto constitutivo de la literatura eslovena- empieza a estimarse menos que la creación poética propiamente dicha (Stanovnik, 2005: 51-67) y a ubicarse en una postura literaria marginal5. Todo esto influye sobre el hecho de que el centro empiece a predominar, separándose de la periferia. Pero para que esto ocurra, hay que dar marcha atrás y volver hasta el barroco.

2 El campo literario a la vez lo determinan dos fuerzas principales, la fuerza centrípeta que centraliza la tradición estética y la fuerza centrífuga que a este proceso de centralización se opone con el proceso opuesto, el de la diseminación (Bhabha, 2006: 81) y el policentrismo. Para el nacimiento y el fortalecimiento de cada literatura nacional es decisiva la fuerza centrípeta.

3 En la literatura eslovena, la aparición de los géneros populares coincide con el nacimiento de la prosa canonizada (Hladnik, 1983: 72).

4 En este contexto cabe destacar la querella entre Jernej Kopitar (1780-1844) y Prešeren y Čop. Kopitar sostenía que la norma lingüística de la lengua eslovena debía basarse en la lengua tradicional (caso que se aplicó con éxito en Serbia, como lo demuestra el caso de Vuk Stefanović Karadžić (1787-1864); Prešeren y Čop a su vez lucharon para que la lengua siguiera como norma la lengua cultivada.

5 Según la teoría de los polisistemas, la traducción puede ocupar la posición central tan solo en literaturas perifericas, débiles (Even-Zohar, 1990: 47; Dovič, 2003: 80). 
Es la época del Barroco la que según varios teóricos -tanto los filósofos y los teóricos de estética (Tatarkiewicz, 1995), como los historiadores de literatura (Kos, 1987) - representa aquella ruptura que en el centro de la expresión literaria sitúa la función estética. Pero esto significa también, como sostiene Zoran Kravar, que dentro de la literatura europea pueda percibirse la coexistencia de dos tipos distintos de literatura: la postrenacentista de las literaturas occidentales de carácter estético, por una parte, y, por otra, la prerrenacentista de carácter pragmático, utilitario y semiliterario de las literaturas centroeuropeas y las del Oriente europeo (Kravar, 1987: 36). Esto no solo quiere decir que exista, por lo tanto, una unificación mayor entre las literaturas occidentales, sino también supone una diferencia abismal entre las más destacadas creaciones de la literatura occidental por un lado -en la que, dicho sea de paso, los logros del arte canónico empiezan a bajar hacia las capas sociales más bajas (Kravar, 1987: 39) donde hay un poeta en cada calle (como se quejaba Lope de Vega)-, y, por otro lado, el corpus literario de las literaturas centroeuropeas y, entre ellas, también la literatura eslovena, a la que, como sucede con la mayoría de las literaturas del Imperio Austrohúngaro, el Barroco alcanza en forma de estilo con función utilitaria sin fines estéticos (Kravar, 1987: 40), y en la que entre 1615 y 1672 hasta puede percibirse un estancamiento literario durante el cual no sale publicado ningún libro en esloveno. Esto, en breve, explica por qué el punto cero, el punto de arranque de la literatura eslovena se halla precisamente en el Barroco y por qué, una y otra vez, la literatura eslovena tiene que volver a la estética del Barroco antes de poder dar un paso hacia delante.

Al hablar de la literatura del Seiscientos no debemos limitarnos tan solo a los textos más logrados, canónicos del Barroco literario occidental, sino también a aquellos ejemplos del Barroco religioso, utilitario sin fines estéticos, y asimismo a las muestras del gusto popular que, a su vez, se ven reflejados en distintos géneros literarios que abarcan tanto la poesía, la novela, como la dramática. Tan solo con vistas a este doble carácter del Barroco, apreciable, por ejemplo, en la literatura áurea española (Maravall, 1990; García de Enterría, 1973; Pregelj, 1999), cabe pensar el hecho de que «la poesía profana eslovena naciera bajo el signo del barroco», como sostiene Boris Paternu en su ensayo Dos fases del barroco en la poesía eslovena (Dve fazi baroka v slovenki poeziji) de $1998^{6}$. Esta es la aporía -que a veces sigue revelándose como una tarea pendiente- que ha tenido que ir asumiendo la historia de la literatura eslovena. La consecuencia de este proceso -en mi opinión tampoco del todo

6 Para subrayar su tesis, Paternu se refiere a la literatura alemana. 
asumido- ha sido tener que aceptar la idea de que el Barroco en la literatura eslovena durante mucho tiempo no fue un periodo concluído, sino un tiempo por cumplir. A continuación enumeraré algunos ejemplos.

En un mundo donde hace mucho todo parece ya estar dicho puede resultar asombroso que sigan apareciendo nuevos documentos del siglo XVII. Pues es el caso de los textos literarios eslovenos ${ }^{7}$ que para la historia literaria funcionan a manera de analepsis, escenas retrospectivas que (ligeramente) han logrado modificar la imagen del carácter predominantemente religioso de la literatura del Seiscientos esloveno. Uno de ellos - no el más reciente, ya que fue encontrado en el año 1888- es el poema Roža zjutraj cvete (La rosa florece por la mañana), de un autor anónimo, supuestamente del año 1643, que tematiza el tiempo, como ya lo promete el mismo título:

Roža zjutraj cvete

z njo lipoto vse razveseli, zvečer doli jemle, čez noč se cilú posuši; takú vas tudi svejt slepí nu njega vesêle. (Gspan, 1978: 95)
La rosa florece por la mañana alegrando, con su belleza, a todos, al atardecer se inclina durante la noche incluso se marchita; y así también el mundo os engaña con su alegría. ${ }^{8}$

Si este poema breve (en una traducción improvisada) con rima asonante acaso puede albergar alguna duda sobre si de veras se trata de un poema profano o más bien de una paráfrasis del versículo 4-6 del Salmo 90 (Svetina, 2006: 157), en la poesía del agustino descalzo Felix Anton Dev - Janez Damascen (1732-1786), editor del primer almanaque poético esloveno Pisanice od lepeb umetnosti (1779-1781), se percibe un claro carácter profano. También en este caso podemos hablar de una especie de anacronismo: aunque se trata de un autor de la Ilustración, algunas poesías suyas, tanto a nivel temático como a nivel formal, recuerdan al Seiscientos como es entre otros el caso del poema Pudlbal (Carnaval), publicado en el segundo volumen del almanaque. En el subtítulo al autor alude a Gottfried Benjamin Hancke, el autor de Barroco tardío alemán de quien tomó prestado el texto para adaptarlo al esloveno9. Aunque las tres partes del poema lo ocupa la descripción de los efectos carnavalescos del evento, éstos se acumulan para desembocar en una

7 Últimamente, han sido publicados varios manuscritos eslovenos de los siglos XVII y XVIII (en: http://ezb.ijs.si/fedora/get/nrss:nrss/VIEW/).

8 La traducción, como todas que se ofrecen a continuación, excepto cuando está mencionado el traductor, son de la autora del artículo y está hecha muy literamente.

Como ha demostrado Jože Koruza (1993: 200), se trata de una adaptación muy libre. 
oposición entre el espíritu frívolo del baile y una reflexión moral que termina con los siguientes versos:

Ni tudi svejt en bal? Kjer kar je le mogoče

Vsak skriti tu, kar je; vsak bit' tu, kar ni, oče.

Ni tud' tukej en vovk pod ovčjo kožo skrit?

Ni tud' en Judež tu v perjazne plajš zavit?

$\mathrm{Ni} v$ tu, kar gugle nas, Karibdis spreminena?

$\mathrm{Ni}$ tu, kar zible nas, ena sladna Sirena?

$\mathrm{Ni}$ tu, kar liže nas, en Joabinske spak?

$\mathrm{Ni}$ tu, kar glade nas, en mačk, en lisjak?

$\mathrm{Ni} v$ tem skrit en goluf, katire nam persega?

$\mathrm{Ni}$ un en izdajavc, k'tir z nami v skledo sega?

$\mathrm{Ni}$ ta en šulc, katir’ živeti nam želi?

Ni ta pod varham skrit, k'tir v jamo nas teši?

$\mathrm{Ni}$ vse sprebernenu, zagernenu, zakritu?

$\mathrm{Ni}$ vse tu šemastu, lažnivu in zavitu?

Al pišu vtihne mi, us pisk je nje zastal.

Zadosti sem jest pejl. Us svejt je pudelbal. (Pisanice, 1780: 73)

¿Acaso el mundo no es un carnaval, en el que

cada uno puede esconder lo que es, ser lo que no es?

¿Acaso aquí, bajo la piel de oveja, no se esconde un lobo?

¿Acaso no es Judas el que del amigo se abriga?

¿Acaso no se convierte en Caribdis la que nos remueve?

¿Acaso no es una dulce Sirena la que nos adormece?

¿Acaso no es lo que nos adula un monstruo de Joabe?

¿Acaso no es lo que nos acaricia un gato, un zorro?

¿Acaso en esto no se esconde un estafador que nos jura?

¿Acaso éste no es un traidor que toma del mismo recipiente que nosotros?

¿Acaso no es un desleal el que nos desea la vida?

¿Acaso no se esconde al lado del hoyo el que dentro nos empuja?

¿Acaso no está todo convertido, cubierto, velado?

¿Acaso no está todo esto enmascarado, falseado y escondido?

Pero todo sonido se ba silenciado, todo sonido está parado.

He cantado lo suficiente. Todo el mundo es un carnaval.

En el poema por un lado se percibe una fuerte tendencia moral (que se corresponde, a su vez, con la tradición utilitaria de la literatura Barroca eslovena, 
sobre todo con los ejemplos ${ }^{10}$ utilizados en la así llamada prosa oratoria), y por otro lado, algunos procedimientos formales típicamente Barrocos: acumulaciones que desempeñan la función de gradaciones, anáforas de efecto dramático, metáforas sinónimas que tematizan el desengaño (cuyos núcleos forman las palabras: lobo, Judas, Caribdis, Sirena, monstruo, zorro, estafador, traidor, desleal - de un carácter muy claro) y llevan a una conclusión -de nuevo una metáfora que describe el mundo como un carnaval- muy Barroca. Además, en el poema de Dev se percibe, según Paternu, una preocupación por el cultivo de la lengua que anuncia la segunda fase del Barroco esloveno que puede apreciarse en la obra de Prešeren (Paternu, 1997-1998: 190), con lo cual a la obra de Dev se le atribuye una función de prolepsis, es decir, de una anticipación de los hechos.

Antes de poder apreciar la importancia del Barroco en Prešeren, cabe mencionar el autor del primer poemario esloveno Pavel Knobl (1765-1830) quien en 1801 publicó Śtiri pare kratkočasnib novib pesmi (Cuatro pares de nuevos poemas entretenidos) con lo cual se anticipó a la publicación de Pesmi za pokušino (Poemas de ensayo) de Valentin Vodnik - publicado a su vez en 1806- a quien hoy en día se considera el primer poeta esloveno, lo cual es lógico, ya que los poemas carnavalescos de Knobl por su carácter satírico no pudieron desempeñar este papel constitutivo que el establecimiento del sistema de la literatura eslovena pedía de los autores eslovenos ${ }^{11}$. No obstante, en los poemas de Knobl, organizados en oposiciones temáticas, puede percibirse un eco de este Barroco efímero que José Antonio Maravall denomina kitsch y María Cruz García de Enterría literatura popular: el poemario de Knobl -que por su forma ${ }^{12}$ podría ser considerado también un pliego de cordel- empieza por una oda a la patata Od podzemnib jabuk (De las manzanas del subsuelo) a la que, a manera de oposición, sigue una oda al pedo Od perdca (Del pedo) de la que cito el inicio:

SOLO.

Kdor enga jetnika

iz ječe spusti, ga hvala velika

povsod obleti.

\section{SOLO.}

El que a un prisionero

lo deja en libertad, será muy alabado en todas partes.

10 En esloveno eksempel, cuentos moralizantes.

11 Tan solo las comedias de Anton Tomaž Linhart de un fuerte caracter nacional han escapado a este destino; el resto de los textos - la mayoría de ellos de carácter popular- han sido rechazados (compárese Štrekelj, 1889 y Dolgan, 1993).

Tiene apenas 40 páginas. 
Vsak človek ima

jetnika doma,

prdec mu je ime,

ah, naj le ven gre!

KOR.

Napnimo fagot,

prdimo povsod,

Tiberiju na čast,

ki je dal to oblast!

(Knobl, 1801: 3)
¡Cada bombre

tiene un prisionero en casa,

se llama pedo,

que se vaya fuera!

CORO.

¡Pongamos el fagote, tirémonos pedos en todas partes, en bonor de Tiberio, quien nos dio este poder!

Y con un estilo parecido sigue este Quevedo esloveno, que si bien en juegos de palabras no alcanza al maestro español, sí le recuerda por su inclinación costumbrista. Además de una fuerte connotación carnavalesca los poemas, tal y como están ordenados el primero y el segundo, representan, en su oposición entre la comida y los excrementos, un referente corporal metonímico del transcurso de la vida humana. $\mathrm{Y}$ aunque el primer poema nos sitúa en un lugar concreto, ya que empieza diciendo que «Un nuevo huésped ha venido a Kranj», refiriéndose a la reforma agraria de las autoridades que incitaban a los campesinos eslovenos a plantar la patata, su ubicación temporal es en realidad alegórica, puesto que en el poema -y a través de un irónico tono laudatoriose critica indirectamente a las autoridades francesas de las Provincias de Iliria, con lo cual el autor se refiere a otro signo anterior -aquí a un pasado, según su opinión del mejor gobierno austríaco- que representa la clave del poema sin el cual éste no puede entenderse del todo, ni tampoco puede apreciarse el significado del segundo poema -emblema- en el que la libertad proclamada por los franceses se lleva hasta el extremo de lo carnavalesco y quizá incluso de algo muy efímero (esta vez tanto en el sentido figurativo - refiriéndose al tiempo estimado de su gobierno, como en el sentido literal - la duración de un pedo).

Es obligatorio incluir a este recorrido breve por la poesía eslovena de carácter Barroco el máximo representante del Romanticismo esloveno. En France Prešeren (1800-1849), sobre todo en su primera fase, los historiadores literarios han apreciado una afinidad al Barroco. Aquí voy a seguir esta línea de investigación que ha iniciado Boris Paternu, aunque a la luz de la obra de Pavel Knobl, quizá deberíamos dedicarnos más a la poesía de su última época que tiene un carácter ocasional y jocoso. No obstante, aquí mencionaré el primer poema publicado de Prešeren (escrito tanto en esloveno como en 
alemán) que tiene un carácter simbólico, es decir, anuncia tanto sus poemas maduros, como sus últimos poemas. El poema Dekletom/Die Mätchen ( $A$ las chicas) -lamentablemente no incluido en la traducción española de su poesía Cantos- inicia el tema del tiempo que es una obsesión constante de su obra, pero a diferencia de los poemas románticos, como es por ejemplo, Slovo od mladosti (Adiós a la juventud), en éste no nos encontramos con la discrepancia existencial entre el sujeto lírico y la sociedad que lo rodea, sino que lo vemos iniciarse con un collige, virgo, rosas muy Barroco tanto en la elaboración del tema, como en el empleo de recursos formales:

Padala nebeška mana

Izraelcam je v pušavi; zginila je, ak pobrana ni bila ob uri pravi.

Kak lepó se rosa bliska, dokler jutra hlad ne mine! Komej sonce bolj pritiska, bo pregnana od vročine.

Rožice cvetó vesele le ob času letne mlade; leto pošlje piš in strele, lepo cvetje jim odpade.

Roža, rosa ino mana naša je mladost, dekleta! Svétjem, naj ne bo zaspana, ki cvetó ji zlate leta.

Fante zbiraš si prevzetna, se šopiriš, ker si zala; varji, varji, de priletna samka se ne boš jokala! (Prešeren, 1974: 6)
Cayó el maná del cielo a los Israelitas en el desierto; desapareció, si recogido no fue a la bora adecuada. ¡El rocío brilla, bello, mientras el frío de la manaña permanece! Cuando el sol apenas calienta el calor lo abuyenta.

Las flores florecen alegres sólo en la época temprana [de primavera]; el verano trae vientos y rayos y las flores se caen.

¿Flor, rocío y maná es nuestra juventud, chicas! Mi consejo a la que florece en la edad dorada, es no ser demasiado lenta.

Escoges a los chicos, eres soberbia, te jactas por ser bella; iten mucho cuidado de que vieja y sola no llores demasiado!

Huelga explicar el carácter simbólico de este poema. Aunque en él se aprecia el empleo del verso octosílabo (típico de la poesía popular eslovena), predominan otros elementos formales, tanto la gradación como la acumulación, por los que el poema recuerda los más destacados logros de la literatura áurea española, aunque también tiene una connotación moral que en los poemas de Garcilaso y Góngora no se percibe. Pero la lectura de los contemporáneos de Prešeren 
fue distinta: como ha señalado Boris Paternu, el poema significaba una provocación contra el moralismo conservador que velaba muy atentamente la poesía eslovena y rechazaba en ella cualquier alusión erótica. En este contexto, la erotización de la parábola bíblica del maná fue considerada una provocación extrema y «un contrasermón poético» (Paternu, 1997-1998: 194) que enunciaba el escándalo provocado por la Corona de sonetos, dedicada (por primera vez en la literatura eslovena) a una mujer de carne y hueso, a Julia Primic. En este sentido, la conclusión del poema tiene en realidad una función irónica al querer afirmar justo lo contrario de lo que se dice, pero hay que decir que esta lectura depende del todo del lector, ya que el poema funciona también si desconocemos la lectura de sus contemporáneos.

Tanto la alegoría, como el símbolo y la ironía que hemos percibido en los poemas de Dev, Knobl y Prešeren tienen, según Paul de Man, características temporales (de Man, 1997: 185-226). La ironía es fundamental también para la poesía de Tomaž Šalamun (Potocco, 2012) quien no solo cambió un verso conocido de Duma de Oton Župančič («Hodil po zemlji sem naši in pil nje prelesti» / Andaba por nuestra tierra, disfrutando de sus maravillas un poema de carácter nacional) a «Andaba por nuestra tierra y me salió una úlcera de estómago», sino que renunció a la tradición poética eslovena ya con su primer poema escrito, un archiconocido poema provocador del ciclo Mrk (Eclipse):

Me cansé de la imagen de mi tribu

y emigré.

De largos clavos

me sueldo los miembros del cuerpo nuevo.

De trapos viejos serán las entrañas.

Una pútrida capa de carroña

será la capa de mi soledad.

Extraigo mi ojo desde lo profundo del pantano.

Con las planchas carcomidas del asco

levantaré mi barraca.

Mi mundo será un mundo de bordes filosos.

Cruel y eterno ${ }^{13}$.

(Šalamun 1999)

También en este poema-bofetada se perciben algunos procedimientos típicos de estilo Barroco: los hipérbatones, las metáforas de la putrefacción

13 Traducción de Juan Pablo Fajdiga. 
y de la transformación (como agudamente ha notado Miklavž Komelj, 2007), y sobre todo las catacresis que representan el procedimiento poético principal de la obra de Šalamun (Paternu, 2003; Pregelj, en prensa). Al querer demostrar la imposibilidad de nuestra historicidad, como afirma Paul de Man, la ironía tiende a expandirse hasta llegar a su plenitud momentánea que es el infinito (de Man, 1997: 218). Y esto es exactamente lo que logra el poema de Šalamun.

Al aludir a la última cumbre de la poesía eslovena hemos dibujado los principales puntos del mapa del Barroco literario esloveno. Si bien hasta cierto punto éste se aproxima a la noción atemporal del estilo barroco, es decir, puede ubicarse en el eje metafórico, también, y a la vez, debe situarse en el eje metonímico. Según sostiene Paul de Man, de la dialéctica y de la coexistencia de los dos modos de la expresión lingüística (Jakobson) y literaria (Lodge) se compone la historia literaria. Como la historia literaria es un proceso dinámico, precisamente a causa de la importancia que tiene para la literatura eslovena, el Barroco puede ser considerado aquella noción -aquel conceptoescurridiza cuyo significado iterable (Derrida) siempre se desplaza (Lacan) y que por lo tanto es imposible de definir.

\section{Bibliografía}

Bhabha, H. (2006): «Diseminación. El tiempo, el relato y los márgenes de la nación moderna». En: Dolores Romero López (ed.), Naciones literarias. Rubí (Barcelona) Anthropos Editorial, Madrid: Servicio de Publicaciones de la Editorial Complutense, 69-112.

Bilban, T. (2010): «Natrgani in preobrnjeni čas med stranmi sodobnega romana». En: Primerjalna književnost, 33, 1, 23-39.

Dolgan, M. (1993): «Okrogle in kosmate». En: Marjan Dolgan, Miran Hladnik (eds.), Fuk je Kranjcem v kratek čas: antologija slovenske pornografske poezije s pripovednim pristavkom. Ljubljana: Mihelač, 143-193.

Dolinar, D. (2007): Med književnostjo, narodom in zgodovino: razgledi po starejši slovenski literarni vedi. Celje-Ljubljana: Celjska Mohorjeva družba Založba ZRC, ZRC SAZU.

Dović, M. (2003): «Literarni polistem in mehanizmi medkulturnih stikov». En: Jezik in slovstvo, 48, 6, 75-85.

Even-Zohar, I. (1990, 1997): «Polysystem Studies». En: Poetics Today, 11, 1, $1-268$. 
García de Enterría, M. C. (1973): Sociedad y poesía de cordel en el Barroco. Madrid: Taurus.

Godzich, W. (1998): Teoría literaria y crítica de la cultura. Madrid-Valencia: Cátedra-Fróntesis.

Gspan, A. (ed.) (1978): Cvetnik slovenske vezane besede. Ljubljana: Slovenska matica.

Hladnik, M. (1983): Trivialna književnost. Ljubljana: DZS.

Hladnik, M. (2001): «Ne, na Parnas pa že ne!». En: 37. seminar slovenskega jezika, literature in kulture: Zbornik predavanj. Ljubljana: Center za slovenščino kot drugi/tuji jezik pri Oddelku za slovenistiko Filozofske fakultete Univerze v Ljubljani, 115-138.

Hutcheon, L. (2006): «Repensar el modelo nacional». En: Dolores Romero López (ed.), Naciones literarias. Rubí (Barcelona)-Madrid: Anthropos Editorial - Servicio de Publicaciones de la Editorial Complutense, 231304.

Jauss, H. R. (1995): «Recepcijska teorija - retrospektiva njene ne(pre) poznavne predzgodovine». En: Aleš Pogačnik (ed.), Sodobna literarna teorija. Ljubljana: Krtina, 157-176.

Jesenšek, M. (2010): «Slovenski knjižni jezik med središčem in obrobjem normativnost in/ali partikularizem». En: Irena Novak-Popov (ed.), Vloge središča: konvergenca regij in kultur, Ljubljana: Zveza društev Slavistično društvo Slovenije, 13-22.

Kmecl, M. (2004): Tisoč let slovenske literature. Drugačni pogledi na slovensko literarno in slovstveno preteklost. Ljubljana: Cankarjeva založba.

Komelj, M. (2007): «O pesniških postopkih v novejši poeziji Tomaža Šalamuna. Pesniku za 66. rojstni dan». En: Tomaž Šalamun, Sinji stolp. Ljubljana: Študentska založba, 99-150.

Koruza, J. (1993): Značaj pesniškega zbornika 'Pisanice od lepeb umetnost'. Maribor: Obzorja.

Kos, J. (1987): «Madame de La Fayette in začetki evropskega romana». En: Madame de La Fayette, Kneginja Klevska. Ljubljana: Cankarjeva založba, 5-54.

Kravar, Z. (1987): «Barok kao potonulo kulturno dobro». En: Aleksander Skaza, Ada Vidovič-Muha, Jože Sever (eds.), Obdobje baroka v slovenskem jeziku, književnosti in kulturi: Mednarodni simpozij v Ljubljani od 1. do 3. julija 1987. Ljubljana: Univerza Edvarda Kardelja v Ljubljani, Filozofska fakulteta. 
Mainer, J. C. (2006): «La invención de la literatura española». En: Dolores Romero López (ed.), Naciones literarias. Rubí (Barcelona)-Madrid: Anthropos Editorial - Servicio de Publicaciones de la Editorial Complutense, 201-230.

Man, P. de (1997): Slepota in uvid. Ljubljana: LUD Literatura.

Maravall, J. A. (1990): La cultura del Barroco: análisis de una estructura bistórica. Barcelona: Ariel.

Melo Miranda, W. (1994): «Nações literárias». En: Revista Brasileira do Literatura Comparada, 2, 31-38.

Ožbot, M. (2006): «Slovensko-italijanski kulturni odnosi skozi prizmo književnega prevajanja». En: Barbara Pregelj (ed.), Literatura v večkulturnem položaju in ustvarjalno delo Jolke Milič. Nova Gorica: Univerza, 21-26.

Ožbot, M. (2011): «Translation as an Agent of Culture Planning in LowImpact Cultures». En: Antoine Chalvin, Anne Lange, Daniele Monticelli (eds.), Between cultures and textes: itineraries in translation bistory: itinéraires en bistoire de la traduction. Fráncfort del Meno [etc.]: P. Lang, 55-66.

Paternu, B. (1987/98): «Dve fazi baroka v slovenski književnosti». En: Jezik in slovstvo, 43, 5, 187-194.

Paternu, B. (2003): «O Šalamunovi poeziji». En: Tomaž Šalamun, Od tam. Ljubljana: Mladinska knjiga, 181-190.

Pisanice od lepeb umetnost ([1779-1781] 1977). Facsímile. Ljubljana: Mladinska knjiga.

Potocco, M. (en prensa): Kult pesniškega jaza ter romantična ironija pri Tomažu Šalamunu in Urošu Zupanu (in še nekaj malega o retoričnih sredstvih) En: Krištof Jacek Kozak, Barbara Pregelj (eds.), Obnebja jezika: Poezija Tomaža Šalamuna. Koper: Annales.

Pregelj, B. (1999): «El kitsch en el Barroco castellano». En: Verba Hispanica, $8,70-100$.

Pregelj, B. (2006): «Španske romance pri Stanku Vrazu». En: Martina Ožbot (ed.), Prevajanje besedil iz prve polovice 20. stoletja. Ljubljana: Društvo slovenskih književnih prevajalcev, 329-339.

Pregelj, B. (2010a): «Literarni ustvarjalci slovenskega zahoda in slovenski literarni kanon». En: Katja Mihurko Poniž (ed.), Ljubka Šorli (19101993): znanstvena monografija ob stoletnici pesničinega rojstva. Nova Gorica: Univerza, 177-191. 
Pregelj, B. (2010b): «O sredobežnosti sodobne slovenske proze». En: Irena Novak-Popov (ed.), Vloge središča: konvergenca regij in kultur. Ljubljana: Zveza društev Slavistično društvo Slovenije, 284-290.

Pregelj, B. (en prensa): «Eternidad prevoda». En: Krištof Jacek Kozak, Barbara Pregelj (eds.), Obnebja jezika: Poezija Tomaža Šalamuna. Koper: Annales.

Prešeren, F. (1974): Pesnitve in pisma. Ljubljana: Mladinska knjiga.

Pretnar, T. (1997): «Novi zvrstni polifunkcionalni verzni vzorec in zlogovnonaglasno verzno izročilo: Prešernov in Vrazov jambski enajsterec». En: Aleš Bjelčevič (ed.), Iz zgodovine slovenskega verznega oblikovanja. Ljubljana: Znanstveni inštitut Filozofske fakultete, 75-87.

Stanovnik, M. (2005): Slovenski literarni prevod 1550-2000. Ljubljana: Založba ZRC, ZRC SAZU.

Svetina, P. (2006): «Poezija med salonom in klozetom: iz življenja starejše slovenske posvetne poezije». En: Peter Svetina, Od lubezni in vesela: izbor iz starejše slovenske posvetne poezije. Ljubljana: Mladinska knjiga, 149-168.

Šalamun, T. (1999): Selección de poemas. Madrid: Visor.

Štrekelj, K. (1889): «Predgovor». En: Karel Štrekelj, Slovenske narodne pesmi, 1. Ljubljana: Tiskarna Rudolfa Milica, V-XV.

Tatarkiewicz, W. (1995): Historia de seis ideas. Arte, belleza, forma, creatividad, mímesis, experiencia estética. Madrid: Tecnos. 


\author{
Barbara Pregelj \\ University of Nova Gorica \\ University of Primorska
}

\title{
The concept of time in Slovenian history: the case of Slovenian Baroque
}

Keywords: Slovenian literary history, Baroque, periodisation, Slovenian literature

Time, no doubt represents one of the central literary topics both in general and in relation to particular literary periods, one of them being the baroque period. Time also represents the central axis of literary history and the fundamental principle for its restoration. Peripheral, so-called "weak" literatures have some specific characteristics with regard to the concept of time, since time is sometimes represented not as linear but takes on anachronisms, analepses and prolepses.

This paper explores certain forms of anachronisms in the Baroque period of Slovenian literature. Since the $17^{\text {th }}$ century has been regarded as the first mainly aesthetic period in western literature, Slovenian literature, which prior to the age of enlightenment was religious, takes a different turn with the works of various authors (e. g. various anonymous writers, Janez Damascen Dev, Pavel Knobl, France Prešeren, Tomaž Šalamun) and different poetic forms harking back to the artistic models of seicento, in order to be able to reestablish itself as a complete aesthetic creation. 
Barbara Pregelj

Univerza v Novi Gorici,

Univerza na Primorskem

\section{Kategorija časa v literarni zgodovini: primer slovenskega baroka}

Ključne besede: slovenska literarna zgodovina, barok, periodizacija, slovenska književnost

Čas je nedvomno ena osrednjih literarnih tem, pa tudi ena temeljnih tem nekaterih literarnih obdobij, denimo obdobja baroka. Čas pa je tudi osrednja os literarne zgodovine in temeljni príncip, po katerem se ta ravna. Ravno pri apliciranju časa na časovnico literarne zgodovine, pri periodizaciji, ponujajo periferne, »šibke« literature vrsto zanimivosti, saj v njih časovno zaporedje večinoma ni linearno, pač pa ponuja vrsto anahronizmov, analeps in proleps.

V članku avtorica izpostavlja nekatere oblike anahronizmov, ki jih ponuja slovenski barok. Ker 17. stoletje velja za prvo estetsko obdobje zahodne literature, se tudi slovenska literatura, ki je vse do razsvetljenstva pretežno nabožna, $\mathrm{v}$ različnih obdobjih in pri različnih avtorjih (Roža zjutraj cvete anonimnega avtorja, Pudlbalu Janeza Damascena Deva, Odperdca Pavla Knobla, Dekletam Franceta Prešerna, Mrku Tomaža Šalamuna) vrača k umetniškemu izrazu seicenta, da bi se lahko vzpostavila kot avtonomni estetski izraz. 